\title{
O PAPEL DO DESIGN NA GESTÃO DE RESÍDUOS DA INDÚSTRIA DE CONFECÇÃO: uma proposta de produto
}

\author{
Heliana Márcia Santos \\ UNESP - PPGDesign \\ helianamsantos@gmail.com \\ Bruno Montanari Razza \\ Universidade Estadual de Maringá [UEM] \\ bmrazza@uem.br \\ João Eduardo Guarnetti dos Santos \\ UNESP - PPGDesign \\ guarneti@feb.unesp.br
}

Resumo: A produção do vestuário gera um volume grande de resíduos têxteis que podem ser reaproveitados para a geração de novos produtos. Neste contexto, é papel do design desenvolver soluções criativas para esses problemas. Atualmente, as preocupações com o meio ambiente estão diretamente ligadas à qualidade de vida e às futuras gerações, o que torna a procura por produtos com desenvolvimento sustentável agregado a responsabilidade social. A indústria têxtil gera desperdícios em quantidades consideráveis, nomeadamente as confecções, através das aparas, retalhos e peças rejeitadas. A indústria de confecção de vestuário é o setor principal na produção de bens finais dentro da cadeia de produção têxtil, no entanto, o ciclo de vida da maior parte dos produtos produzidos pelas confecções é curto, durando cerca de seis meses. O objetivo deste artigo é pontuar o papel do design como um dos agentes responsáveis para o desenvolvimento de novos produtos inseridos na gestão de resíduos das indústrias de confecção e apresentar uma proposta de produto inserido neste contexto. O material desenvolvido com o descarte das indústrias de confecção traz uma proposta para o desenvolvimento de têxteis de forma sustentável. Tendo em vista a responsabilidade social do designer de moda, a proposta de ação sustentável apresentada neste trabalho se aplica na conscientização de se reutilizar materiais já descartados, economia de um novo processo industrial relacionado à extração de recursos naturais, redução da poluição com o descarte de resíduos envolvidos no processo e interagir com a sociedade para introduzir essa consciência no consumo de produtos de origem reciclada.

Palavras-chave: Design, Resíduos Têxteis, Sustentabilidade, Confecção. 


\begin{abstract}
The garment industry produces a high amount of residual fabric that can be reused in order to make new products. In this context, it is a role of the design to propose creative solutions to these problems. Currently, concerns about the environment are directly linked to life quality and future generations, which make the demand for sustainable products with assembled social responsibility. The textile industry generates a considerably high amount of waste, specially the clothing industry with retail and rejected products. This is the main sector in the production of final goods in the chain of textile production; however, the life cycle of most of the products produced by the clothing industry is short, lasting about six months. This paper had as a goal to point out the design role as an agent responsible to the development of new products reusing wastes generated by the garment industry, and to present a proposition of product design inserted in the sustainable context. The material developed with the discarded material of the clothing industries brings a proposal for the development of sustainable textiles. considering the social responsibility of the fashion designer, the sustainable action presented in this paper applies the awareness of reuse materials already discarded, saving a new industrial process related to natural resource extraction, pollution reduction with the disposal of residues involved in the process and the interaction with society to bring this awareness in the consumption of clothes made with recycled fibers.
\end{abstract}

Keywords: Design, Textile waste, Sustainability, Garment.

\title{
1. INTRODUÇÃO
}

As indústrias de confecção do vestuário compõem um dos principais setores produtivos do país e geram uma grande quantidade de resíduos, sendo boa parte composta de sobras de tecido, que apresentam um grande potencial para sua reutilização. Do ponto de vista da sustentabilidade, é papel do design desenvolver soluções que atuem minimizando esses impactos ambientais (KAZAZIAN, 2005; MANZINI; VEZZOLI, 2005), com a geração de produtos que não apenas atrasem um descarte que seria inevitável, mas também que realmente ampliem o ciclo de vida do material.

A responsabilidade social do designer envolve a conscientização de se reutilizar materiais, poupando um novo processo industrial, pensar em projetos mais sustentáveis dentro do processo industrial, preocupar-se com o descarte de resíduos envolvidos no processo, dentre outros. Essas ações devem interagir com a sociedade para introduzir essa consciência e avaliar o uso do produto produzido com o material reciclado (ou recuperado a partir de resíduos) e transformado em algo novo. Para essas soluções serem viáveis, é imprescindível que se faça a verificação da qualidade do produto gerado com esse material reaproveitado.

O objetivo deste artigo é pontuar o papel do design como um dos agentes responsáveis para o desenvolvimento de novos produtos inseridos na gestão de 
resíduos das indústrias de confecção e apresentar uma proposta de produto inserido neste contexto.

\section{A INDÚSTRIA DA CONFECÇÃO}

A confecção em massa permite produzir grandes quantidades a baixos custos, possibilitando vendas elevadas. Pode ser consumida por muitos e é caracterizada por uma grande rotatividade, estando constantemente a serem comercializadas novas peças e modelos de roupas. Sendo assim, a indústria do vestuário tem como objetivo produzir roupas que tenham apelo comercial e acompanhem as tendências culturais, tecnológicas e de comportamento (JONES, 2005).

Sudjic (2010) compreende a moda como um processo de transformação dos tecidos em roupas, em escala industrial. E o sistema de moda tem sido a força motriz da industrialização, pois "depende de todo tipo de engenhosidade tais como: técnicas de produção de massa, fabricação e tintura do tecido, distribuição baseada em princípios de minimização de estoques, criatividade dos designers e a habilidade com que seu trabalho é usado para criar a aura que dá às roupas a sua sedução. Porém, a moda ainda é tratada como frivolidade" (SUDJIC, 2010, p. 150).

A Indústria de Confecção de Vestuário atende a uma necessidade básica do ser humano: o vestir (PEZZOLO, 2007). Na cadeia têxtil, cujas etapas industriais vão desde o beneficiamento das fibras até a confecção de peças prontas para o uso, a confecção é a última atividade industrial antes da comercialização, e produz, em escala industrial, peças de vestuário a partir de tecidos planos ou malhas (JONES, 2005).

$\mathrm{Na}$ cadeia produtiva têxtil, as fibras naturais são as mais conhecidas, compreendendo: a seda, a lã, os pelos e as crinas de origem animal; e os caules que permitem a extração de fibras de origem vegetal, como algodão, linho, cânhamo, juta (CHATAIGNER, 2006). As fibras químicas abrangem as fibras sintéticas, derivadas de produtos petroquímicos, e as artificiais derivadas da celulose (CHATAIGNER, 2006).

A Agência Brasileira de Desenvolvimento Industrial (ABDI; UNICAMP, 2008) relatou uma melhora na capacidade produtiva e crescimento na economia brasileira, considerando dentro da cadeia têxtil os subsetores: fibras têxteis, fiação e tecelagem, petroquímica (fios sintéticos) e os artefatos têxteis. Estes setores foram as maiores fontes geradoras de emprego em relação aos outros setores da economia brasileira. Destaca-se também que muitos desses empregos gerados ainda são de qualificação inferior e localizados principalmente na obtenção de fibras naturais.

Segundo dados da Abit- Associação Brasileira da Indústria Têxtil e de Confecção referentes ao ano 2013 o setor têxtil e de confecção no Brasil é o quarto maior parque produtivo de confeç̧ão do mundo e o quinto maior produtor têxtil do mundo; segundo maior produtor e terceiro maior consumidor de denim do mundo; a moda brasileira está entre as cinco maiores Semanas de Moda do mundo. A estimativa do Faturamento da Cadeia Têxtil e de Confecção em 2013 foi de US\$ 53 bilhões. A Produção média de confecção foram 9,8 bilhões de peças; (vestuário; cama, mesa e banho); o setor emprega 1,7 milhões de empregados diretos, dos quais $75 \%$ são de mão de obra feminina; é o segundo maior empregador da indústria de transformação, representa $16,4 \%$ dos empregos e $5,5 \%$ do faturamento da Indústria de Transformação, tem cadastrado 30 mil empresas em todo o País. O Brasil é, ainda, a última Cadeia Têxtil completa do Ocidente, temos desde a produção das fibras, como plantação de algodão, até os desfiles de moda, passando por fiações, tecelagens, 
beneficiadoras, confecções e varejo. Brasil é referência mundial em design de moda praia, jeanswear e homewear, tendo crescido também os segmentos de fitness e lingerie (ABIT, 2014).

Segundo as informações da ABDI - UNICAMP (2008), houve deslocamento de atividades produtivas através de investimento direto ou terceirização/subcontratação para regiões ou países em que o custo do trabalho é baixo, principalmente no exterior, nas regiões da Ásia, América Central e Caribe, países do norte da África e leste europeu. Também ocorreu no Brasil a importação de artigos acabados, principalmente da China, quando grandes empresas do ramo de tecelagem transferiram unidades produtivas para o Nordeste em busca de custos mais reduzidos de trabalho e de benefícios fiscais. Por isso, os sistemas de produção locais continuam a exercer atração sobre as pequenas e médias empresas; neste caso da indústria do vestuário, existe uma tendência de organização espacial das empresas de menor porte em torno de polos. Os exemplos mais conhecidos são os polos de Americana (SP), Vale do Itajaí $(S C)$, Cianorte (PR), Maringá (PR), São João Nepomuceno (MG), Nova Friburgo (RJ) e Jaraguá (GO).

\section{RESÍDUOS GERADOS NA CONFECÇÃO}

De um modo geral, toda atividade industrial gera resíduos como subprodutos, os quais provocam impactos ambientais, seja devido aos processos produtivos, aos próprios materiais utilizados, ou pelo descarte dos produtos ao final de seu ciclo. Denomina-se resíduo a sobra ou o que resta de um processo produtivo, e que será descartado. São insumos não aproveitados ou desperdiçados nos processos produtivos que, apesar de considerados inevitáveis, são indesejáveis por não apresentar valor comercial significativo (ALENCAR; ASSIS, 2009).

Os resíduos têxteis, retalhos e aparas de confecção estão classificados como Resíduo Classe II-A (não inerte), pois apresentam propriedades como biodegradabilidade, combustibilidade ou solubilidade em água, segundo a Norma Brasileira (NBR) 10.004/2004 (ABIT, 2012; ALENCAR; ASSIS, 2009).

Alencar e Assis (2009) identificaram 54 tipos de resíduos que podem ser gerados pelo setor de confecções, sendo que alguns são específicos do setor, como:

- retalhos: sua geração ocorre, principalmente, na fase de corte, como resultado do limite da eficiência da modelagem manual ou automatizada (CAD/CAM). A geração de retalhos pode atingir até $30 \%$ do total inicial de tecido plano ou malha;

- pó de overloque: proveniente das máquinas de costura refiladoras - sua geração tem relação com o excesso de tecido deixado na fase do corte;

- carretéis plásticos: provenientes de linhas e elásticos das etapas de costura e bordados;

- tubos de papelão e de PVC: gerados por tecidos e papel utilizado nos moldes, adquiridos em rolos;

- outros resíduos: agulhas, linhas de acabamento e arremates, lâmpadas, embalagens de óleo lubrificante, tecidos ou estopas sujas, utilizadas na limpeza e manutenção das máquinas, dentre outros.

Brendler e Brandli (2011) identificaram os resíduos gerados na indústria da confecção em cada etapa de seu processo produtivo (Figura 1), incluindo, neste caso, também o ruído (não resíduo). Pode-se observar que os retalhos de tecido são gerados em diversas dessas etapas (corte, montagem, finalização e expedição). 


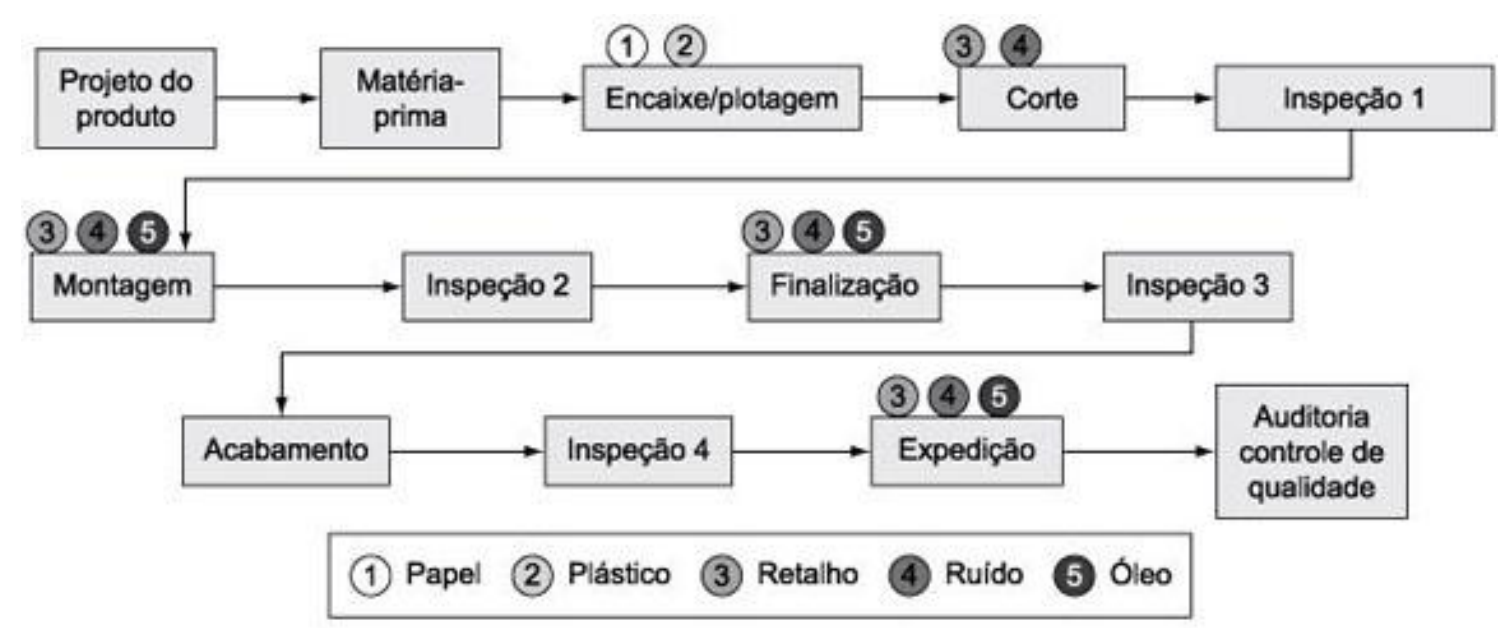

Figura 1: Fluxograma do processo produtivo

Fonte: Brendlere Brandli (2011).

No processo produtivo das Indústrias de confecção do vestuário o setor de corte é onde se encontra maior geração de resíduos têxteis, provenientes de aparas de tecidos que são descartadas depois de separadas das peças que virarão roupas (ARAUJO, 1996).

Considerando a quantidade de resíduos têxteis descartados e o impacto ambiental em termos de geração de lixo, ocupação de aterros sanitários e gastos energéticos para a gestão destes resíduos (MILAN, 2010; ASSIS et al., 2007) são necessárias propostas de reutilização e aumento do ciclo de vida deste material.

O decreto $\mathrm{n}$ - 7.404, de 23 de dezembro de 2010, regulamenta a Lei no 12.305, de 2 de agosto de 2010, que institui a Política Nacional de Resíduos Sólidos, cria o Comitê Interministerial da Política Nacional de Resíduos Sólidos e o Comitê Orientador para a Implantação dos Sistemas de Logística Reversa, reuso e reciclagem, etc. . A lei estabelece um conjunto de princípios, objetivos e instrumentos, para à gestão integrada e ao gerenciamento ambiental adequado dos resíduos sólidos, eliminando até agosto de 2014 os lixões e disponibilizar os rejeitos em locais adequados que não agridam o ambiente (BRASIL, 2014).

Conforme explica Freire e Lopes (2013) a lei, a gestão e o gerenciamento dos resíduos sólidos devem obedecer a uma hierarquia de prioridades, pois um dos objetivos dessa lei, conforme disposto no artigo 70, inciso II, é a não geração, redução (da quantidade e volume gerados), reutilização, reciclagem e o tratamento dos resíduos sólidos, bem como a disposição final ambientalmente adequada dos rejeitos. Isso vai exigir que a sociedade, as organizações e o poder público, passem por mudanças culturais e no comportamento sobre a forma como agem em relação ao seu lixo e seus resíduos.

Desta forma, o destino correto dos resíduos de tecidos utilizados no processo produtivo tem sido uma preocupação emergente do setor, já que o Ministério Público tem exigido das empresas da cadeia produtiva soluções imediatas, por meio de programas de gestão ambiental, visando minimizar as consequências que a inadequada destinação destes resíduos vem ocasionando ao meio ambiente.

Cada vez mais fica evidente a necessidade da execução de práticas voltadas para o aproveitamento de resíduos sólidos, representando uma importante alternativa 
à sustentabilidade e preservação do meio ambiente, que se expressa também, na ausência de conscientização e capacitação dos indivíduos envolvidos no processo produtivo. A prática de ações sustentáveis coloca o meio ambiente no centro da atividade econômica, valorizando as riquezas disponíveis, ao mesmo tempo em que fortalece relações econômicas e sociais com base na estruturação, classificação, armazenamento e destinação adequada dos resíduos (MANZINI, VEZZOLI, 2005; KAZAZIAN, 2005).

\section{O DESIGN E AS PRÁTICAS SUSTENTÁVEIS}

Löbach (2001) afirma, o design se inicia pelo desenvolvimento de uma ideia, podendo se concretizar através de modelos em uma fase de projeto, cuja finalidade seria a resolução dos problemas que resultam das necessidades humanas. Desta forma, o design aparece como atividade especializada e representa uma instância de abstração técnica projetiva, que anteriormente estava distribuída ao longo do processo produtivo, como ocorria com a produção artesanal e, passa, nesse momento, a se concentrar de forma ligeiramente deslocada da execução (Denis 2005).

Sendo assim, Manzini e Vezzoli (2005) sintetizam o papel do design como a atividade que, ligando o tecnicamente possível, com o ecologicamente necessário, faz nascerem novas propostas que sejam social e culturalmente apreciáveis. E a conscientização do problema ambiental levou à discussão e à orientação de novos comportamentos sociais. Ou seja, o entendimento dessa problematização engloba desde a geração de tecnologias limpas, passando pelo desenho de produtos limpos e chegando enfim, ao consumo limpo.

O desenvolvimento sustentável deve conciliar crescimento econômico, preservação do meio ambiente e melhora das condições sociais, ou seja, deve estar inserido na complexidade das interações entre o homem, os objetos que ele concebe e a natureza (KAZAZIAN, 2005). Desse modo, o design para a sustentabilidade deve adotar a metodologia definida pelo Life Cycle Design, onde se entende como aponta Manzzini e Vezzoli (2005), uma maneira de conceber o desenvolvimento de novos produtos tendo como objetivo que, durante todas as suas fases de projeto, sejam consideradas as possíveis implicações ambientais ligadas às fases do próprio ciclo de vida do produto. Ou seja, devem ser consideradas as etapas de pré-produção, produção, distribuição, uso e descarte buscando, assim, minimizar todos os efeitos negativos possíveis.

Em contrapartida, a indústria do vestuário é responsável por significativos impactos ambientais tanto em âmbito nacional como mundialmente, decorrente de seus processos produtivos e do elevado índice de consumo de seus produtos que são descartados muito antes do final do seu ciclo de vida útil. Portanto, é necessário reformular os seus processos produtivos, suas etapas e sequências, com vistas a impulsionar uma produção mais limpa com o intuito de melhorar a eficácia da produção e reduzir seus impactos ambientais.

Segundo Martins et al. (2011), um dos caminhos para contribuir com essa mudança de cenário é o desenvolvimento de um método de produção mais limpa e passível de ser aplicado em indústrias de pequeno e médio porte de confecção, com o intuito de melhorar seus processos produtivos, promover a responsabilidade social e impulsionar ações sustentáveis.

A maioria das empresas do setor do vestuário adota como prática a doação dos 
refugos de tecidos para entidades filantrópicas, Secretaria de Ação Social, escolas, empresas e/ou artesãos que confeccionam artigos utilizando retalhos de tecidos. Porém, de acordo com Martins (et al., 2011), o volume de descarte é muito maior que a capacidade desses órgãos e empresas em absorver o volume de resíduos gerados das indústrias de confecções. Desta forma, pode-se constatar que a implantação da lei de gestão de resíduos certamente gerará grandes preocupações para o setor têxtil.

Neste contexto, é premente o desenvolvimento de soluções que contemplem todo o ciclo de vida dos produtos do setor do vestuário e um dos agentes capazes de produzir mudanças é o design.

Neste trabalho é apresentada uma proposta de produto que utiliza materiais descartados da indústria de confecção de vestuário aproveitando materiais de qualidade que até o momento são considerados lixo. Portanto, foi desenvolvido um sapato a partir de resíduos da confecção, como forma de exemplificar uma possível aplicação do design como gestor de resíduos. Além disso, para a construção deste calçado foram empregadas técnicas artesanais de fácil aprendizagem com o objetivo de permitir a capacitação de indivíduos excluídos do sistema produtivo, que então podem ser reintegrados, por meio de associações ou cooperativas. Os itens a seguir serão dedicados à construção e análise deste calçado.

\subsection{0 material}

O resíduo de confecção utilizado neste trabalho é originário do setor de corte da confecção e foi doado por uma microempresa da região centro-oeste do Estado de São Paulo, produtora de uniformes escolares e roupas para o público feminino. Segundo informações da proprietária, os resíduos são doados para artesãos locais que desenvolvem, em geral, tapetes de tear a partir de retalhos. Foi observado que a empresa não tem preocupação com a destinação final dos resíduos da confecção, terceirizando essa responsabilidade para esses artesãos.

Foram recolhidos $10 \mathrm{~kg}$ de retalhos (já estavam separados de outros resíduos), entre malhas e tecidos planos, de diversas cores (Figura 2).

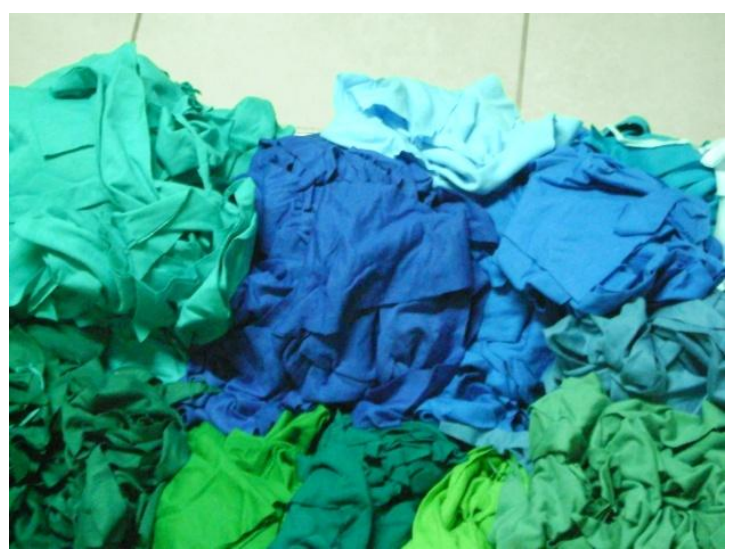

Figura 2. Retalhos

Fonte: do autor.

\subsection{0 produto: sapatilha de tecido}

O modelo de calçado escolhido para o desenvolvimento do protótipo foi uma sapatilha tipo alpargata, pois, segundo Metz (2005), esta apresenta uma baixa complexidade na sua confecção e pode ser realizados por técnicas artesanais. $O$ 
calçado foi desenvolvido no tamanho n. 36, pois conforme Berwanger (2011) esta numeração está entre as mais frequentes na população.

\subsection{O Processo de confecção da sapatilha}

O primeiro processo para a produção do calçado é a preparação das tranças que irão formar o solado. Assim, após a seleção dos retalhos, estes foram cortados em tiras no tamanho de três centímetros de largura; o comprimento das tiras variou conforme o comprimento dos retalhos.

A técnica aplicada para o entrelaçamento foi a trança com três pontas. Neste caso foram empregadas as tiras dos retalhos dispostas em três cores diferentes, pois não havia material suficiente para a execução da trança para o par de sapatilhas com apenas uma cor. O tamanho da trança foi de dois metros de comprimento para cada solado. Neste processo de trançamento não foi aplicado nenhuma cola para a união das tiras, apenas aplicada a força do entrelaçamento das tiras.

Para a execução do solado, as tiras trançadas foram enroladas, conforme as práticas utilizadas em solados de sisal, constituindo de dez voltas para obter o tamanho de $24 \mathrm{~cm}$ que corresponde ao tamanho $\mathrm{n}$. 36, conforme a tabelas de tamanho apresentada por Berwanger (2013). O solado é pespontado manualmente com linha de poliéster para melhor fixar o cabedal e o solado.

O cabedal consiste na parte externa do calçado, formada por uma, duas ou mais peças (MORAES, 2010), e junto com o solado formam o calçado. Para a montagem e o modelo do cabedal que é formado por um tecido que tenha resistência para uso. Ele foi cortado duas vezes (uma parte para cada pé) em tecido plano de fios de algodão e o tipo de ligamento é sarja, que é a ligação de três fios de trama que cruzam com três fios de urdume e que representa uma linha diagonal, característica da ligação da sarja. Esta é uma ligação básica há outras variações (JONES, 2005).

Portanto, cada cabedal foi composto por uma parte de tecido de sarja. O cabedal foi unido por uma costura de máquina reta com ponto classe 300 e tipo 301, é o ponto mais comum e utilizado na confecção e as características deste ponto de costura que ambos os lados são iguais, e as vantagens são: o consumo de linha é menor e as máquinas industriais e domésticas que executam esse ponto são as mais baratas do mercado e de fácil manuseio (ARAÚJO, 1996).

Para a montagem da sapatilha, foram afixados alfinetes na lateral do solado, para juntar o cabedal ao solado e permitir a costura, realizada com margem de $1,5 \mathrm{~cm}$ pra melhor fixação do cabedal no solado (BELMIRO, 1986). A costura para fixar o cabedal foi realizada com agulha manual e linha de poliéster, costurando toda a volta do solado da sapatilha. Para finalizar, foi aplicado um solado de látex no formato do sapato com cola para isolamento do calçado. A tabela 1 apresenta os passos descritos neste item.

Pelo processo de produção e execução, foi possível observar que apenas os retalhos em tamanho maior podem ser utilizados para a produção do calçado. Como os resíduos são doados da indústria de confecção, como sugestão os retalhos recolhidos devem ser separados na própria indústria, pois o artesão teria os retalhos necessários para a execução deste produto e os retalhos menores ficariam na empresa para receberem uma destinação correta, de acordo com a legislação. 
Tabela 1. Processo de produção do calçado.
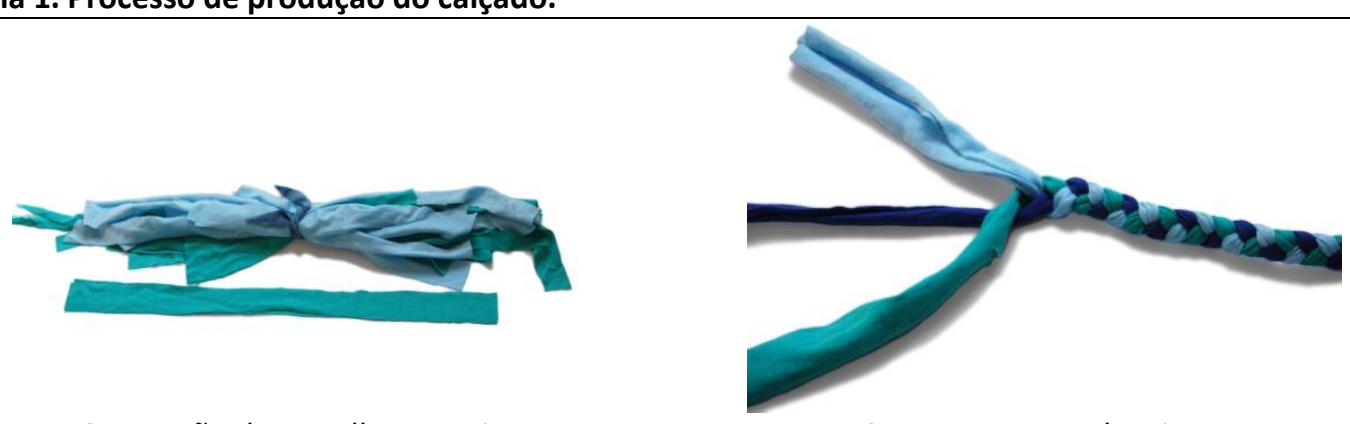

1. Separação dos retalhos em tiras.

2. Trançamento das tiras.
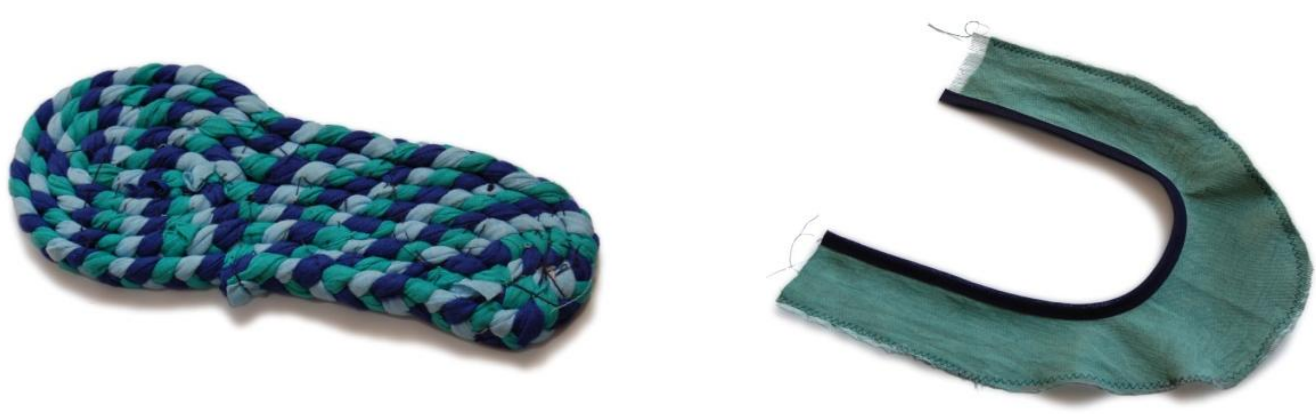

3. Formação da solado.

4. Prepação do cabedal.

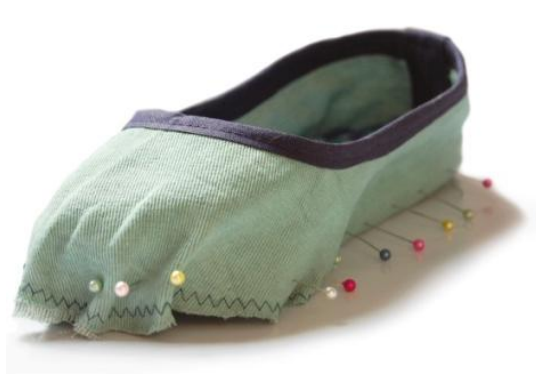

5. Montagem do sapato
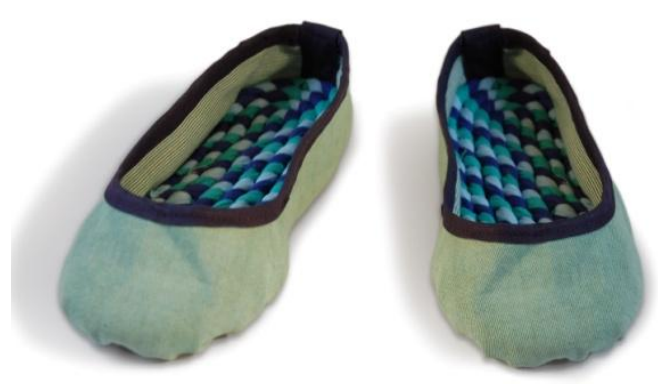

Fonte: do autor.

6. Sapatilha pronta.

Como resultado, pode-se observar que o produto proposto atendeu aos prérequisitos estabelecidos para o desenvolvimento de produto orientado socioambientalmente. Em sua forma de produção utiliza apenas materiais descartados da confecção e pode ser produzido com técnicas artesanais de fácil assimilação, com reduzido uso de tecnologia e pequeno custo de instalação.

Esse sapato pode ser desenvolvido em comunidades artesãs, como cooperativas ou por iniciativa individual, contribuindo com a inclusão social e podendo ser beneficiário de programas governamentais. O papel do designer, neste caso está no de desenvolvimento do produto e treinamento do artesão, trabalhando com a capacitação destes indivíduos. Por fim, sendo um produto sustentável tanto social quanto ambientalmente.

\section{CONCLUSÃO}

No presente artigo, o foco foi justamente a concepção dos produtos do setor considerando o ciclo de vida e, também, os subprodutos passíveis de produção a partir 
dos resíduos do processo de manufatura, Com tal ênfase, cria-se a oportunidade não somente de reduzir custos, mas também de aumentar a competitividade das indústrias por meio da diferenciação em relação aos concorrentes nacionais e internacionais. A dimensão ambiental representa, nesse caso, um dos aspectos de competitividade que tem atraído de forma crescente a atenção do público consumidor.

Com a nova política de gestão de resíduos, as indústrias de confeç̧ão deverão buscar solução para o grande volume de resíduos disponíveis. Atualmente já existem medidas de controle de resíduos e redução de desperdício aplicada amplamente na indústria, especialmente nas de maior porte, mas mesmo assim, o volume de descarte ainda é muito grande.

O descarte da indústria de confecção é uma matéria-prima com grande potencial de utilização, pois é disponível em grande quantidade e se encontra em estado original [sem degradação e quase sempre sem mistura com outros resíduos], mas na forma de retalhos [pequenos pedaços de tecido em formado desigual].

Existem atualmente tecnologias que permitem a reciclagem de tecido, que pode ser empregado nestes resíduos têxteis de forma que eles retornem ao início do processo produtivo como nova matéria-prima (SANTOS; MENEZES, 2012). No entanto, ainda há dificuldades relacionadas ao gasto energético, custos altos de implantação, necessidade de triagem dos tecidos por cor e composição de fibra, problemas de logística e de aceitação do consumidor final.

Conforme discutido anteriormente, um dos papéis do design é de propor soluções por meio de produtos para os problemas sociais e econômicos da sociedade, utilizando de tecnologias e criatividade para gerar melhorias no processo produtivo e nos impactos ambientais. Propostas de produtos que utilizem essa matéria-prima devem ser encorajadas.

Uma possibilidade é o designer trabalhar desenvolvendo produtos que se integrem no próprio sistema fabril da indústria, retornando ao início do processo de produção. Neste caso, a dificuldade é integrar esse produto a um sistema de produção industrial de grande volume, considerando investimentos em maquinários e seriação.

Outra possibilidade é o designer trabalhar com iniciativas sociais, na forma de cooperativas ou pequenas produções independentes, pois os investimentos financeiros podem ser reduzidos e o processo produtivo pode ser mais adaptado ao tipo de material a ser utilizado, os retalhos. O papel o design, neste caso, é de desenvolver produtos e trabalhar com a capacitação de indivíduos, promovendo a integração social e valorização do indivíduo. Estas iniciativas estão de acordo com políticas de desenvolvimento socioambiental, e podem ser beneficiárias de investimentos públicos ou facilidades de financiamento.

Portanto, o design deve assumir o seu compromisso social e utilizar das tecnologias disponíveis e da criatividade para aproveitar essa matéria-prima de qualidade que está sendo literalmente jogada no lixo.

\section{AGRADECIMENTOS}

Apoio Fapesp, processo n. 2013/12204-0.

\section{REFERÊNCIAS}


ABDI; UNICAMP. Relatório de Acompanhamento Setorial Têxtil e Confecção. Volume I. Campinas, 2008. Disponível na internet por http em: <http://www.abdi.com.br/ Estudo/textil\%20e\%20confeccao\%20junho\%2008.pdf>. Acesso em: 21 abr. 2014.

ABIT- Associação Brasileira da Indústria Têxtil e de Confecção. Perfil do setor. Disponível na internet por http em: <http://www.abit.org.br/Imprensa.aspx\#3|LR|C>. Acesso em 28 abr. 2014.

ALENCAR, R. C. S.; ASSIS, S. F. Gestão de resíduos sólidos gerados pelas indústrias de confecção de Colatina/ES. 2009. Disponível na internet por http em: <http://redectidoce.com.br/?secao=artigos_visualizar\&id=1\&artigo=85>. Acesso em: 21 abr. 2014.

ARAUJO, M. Manual de Engenharia Têxtil. Lisboa: Fundação Calouste Gulbenkian, 1984.

BELMIRO, Arnaldo. Como fazer sapatos. Rio de Janeiro: Ediouro. 1986.

BERWANGER, E.G. Antropometria do Pé Feminino em Diferentes Alturas de Salto Como Fundamento para Conforto de Calçados. Dissertação (Mestrado em Design). Universidade Federal do Rio Grande do Sul. Porto Alegre, 2011. Disponível na internet por HTTP em: <http://hdl.handle.net/10183/31577> Acesso 20 abr. 2014.

BERWANGER, E. G. Medidas de formas para calçados femininos no mercado brasileiro. Serviço Nacional De Aprendizagem Industrial - SENAI- RS- Centro tecnológico de Calçados SENAI, 2013. Disponível na internet em http < http://www.sbrt.ibict.br/acessoRT/27699> 17abr. 2014

BRASIL. Decreto no 7.404, de 23 de dezembro de 2010. Regulamenta a Lei n.12.305, de 2 de agosto de 2010. Brasília, 2010. Disponível na internet por http em: <http://www.planalto.gov.br/ccivil_03/_ato2007-2010/2010/Decreto/D7404.htm>.

Acesso em: 23 abr. 2014.

BRENDLER, E.; BRANDLI, L. L. Integração do sistema de gestão ambiental no sistema de gestão de qualidade em uma indústria de confecções. Gestão de Produção.vol.18, n. 1,2011. Disponível na internet por http em: <http://www.scielo.br/scielo.php? pid=S0104530X2011000100003\&script=sci_arttext> Acesso 21 de abril de 2014.

CHATAIGNER, Gilda. Fio a fio: tecidos, moda e linguagem.São Paulo: Estação das Letras, 2006.

FREIRE, Estevão; LOPES, Guilherme Bretz. Implicações da Política Nacional de Resíduos Sólidos para as práticas de gestão de resíduos no setor de confecções. REDIGE - Revista de Design, Inovação e Gestão Estratégica v.4, n.3, 2013. Disponível na internet por wWW em: 
<http://www.cetiqt.senai.br/ead/redige/index.php/redige/article/viewFile/190/234> Acesso em 15 abr. 2014.

JONES, Sue Jenkyn. Fashion design - Manual do Estilista. São Paulo: Cosac Naify, 2005.

KAZAZIAN, T. Haverá a idade das coisas leves: Design e desenvolvimento Sustentável. São Paulo: Editora Senac São Paulo, 2005.

MANZINI, E.; VEZZOLI, C. O desenvolvimento de produtos sustentáveis: os requisitos ambientais dos produtos industriais. São Paulo: EdUSP, 2005.

MARTINS, Susana; SAMPAIO, Cláudio Pereira de; MELLO, Nathalia Castilho. Moda e sustentabilidade; um proposta de sistema de produto- serviço para o setor de vestuário. Revista Projetica v.2, n.1, 2011. Disponível na internet por www em < http://www.uel.br/revistas/uel/index.php/projetica/article/view/10532> Acesso em 20 abr. 2014.

METZ, Cesar Augusto. Fabricação de sapatilhas tipo alpargata. Serviço Nacional de Aprendizagem Industrial - SENAI-RS Centro Tecnológico do Calçado SENAI.2005. Disponível na internet por www em:<www.respostatecnica.org.br/acessoRT/335> Acesso 14 abr. 2014.

MILAN, G. S; VITTORAZZI, C.; REIS, Z. C. A Redução de Resíduos Têxteis e de Impactos Ambientais: Um Estudo Desenvolvido em uma Indústria de Confecções do Vestuário. In: XIII Seminário de Administração. Anais do XIII Seminário de Administração, São Paulo, 2010. Disponível na internet por www em: <http://www.ead.fea.usp.br/semead/13semead/resultado/trabalhosPDF/282.pdf> Acesso 14 abr. 2014

MORAES, Edson Vanderlei. Diferenças entre cabedais. Serviço Nacional De Aprendizagem Industrial - SENAI- RS- Centro tecnológico de Calçados SENAI, 2010. Disponível na internet em http < http://www.sbrt.ibict.br/acessoRT/17152> 17abr. 2014.

PEZZOLO, D. B. Tecidos - História, Tramas, Tipos e Usos. SENAC. São Paulo, 2007.

SUDJIC, Deyan. A linguagem das coisas. Rio de Janeiro; Intrínseca, 2010.

VICENT-RICARD, Françoise. As espirais da moda. São Paulo: Paz e Terra, 1989. 